\title{
Drummond e Augusto de Campos: dialogia de uma tradição contemporânea
}

Luciano B. Justino I UEPA/FFM

Resumo: A proposta deste pequeno ensaio é estabelecer uma correlação entre os poetas Carlos Drummond de Andrade e Augusto de Campos, tentando ligar uma tradição possível da poesia brasileira contemporânea, aberta por Drummond e radicalizada por Campos: a problematização da tradição subjetiva nacional, acentuando as identidades e diferenças entre estes dois poetas.

Palavras-chave: tradição, nacionalidade, identidade.

Para estabelecer a relação entre alguns pontos fundantes da poética drummondiana com a poesia de Augusto de Campos, escolhi dois textos que considero paradigmáticos para o que aqui se pretende; são eles Consideração do poema, de Drummond, publicado em 1945 e Bio, de Augusto de Campos, de 1993. Penso que essa "dialogia" um tanto inusitada pode fazer vislumbrar uma tradição da poesia brasileira contemporânea, que teria em Drummond seu início e em Augusto de Campos sua radicalização crítica. Claro está que falar de uma tal tradição, advinda de um diálogo conscientemente arbitrário entre dois poetas tão diferentes, é saber que o gesto crítico é ao mesmo tempo um olhar objetivo e fragmentador, é a fixação de um ponto a 
partir de onde o observador estabelece uma visada inalienavelmente ideológica, que desnuda a intenção política do ato crítico. Daí este olho se reconhecer como limitado e não impedir, até exigir, outros olhares, que poderia ver inclusive o contrário do olhar anterior.

A trajetória da poesia drummondiana, como é sabido, inicia-se ainda na fase heróica do modernismo brasileiro. Ligada aos padrões estéticos do grupo de 22, assume a coloquialidade, o prosaísmo, a ironia e a necessidade de instaurar um certo desbloqueio crítico dos padrões temáticos advindos dos períodos romântico e parnasiano.

Importa aqui a poesia do autor mineiro cristalizada nos poemas de $A$ rosa do povo, na maturidade de uma poesia agora crítica de sua função e poder na sociedade ocidental e que problematiza seu passado e sua relação com o seu contexto histórico, com seu estágio discursivo, passando por um processo crítico metalingüístico bem típico da poesia européia nas primeiras décadas do século, mas relacionada com as especificidades socioculturais do país.

Não rimarei a palavra sono/ com a incorrespondente palavra outono./ Rimarei com a palavra carne/ ou com qualquer outra, que todas me convêm./ As palavras não nascem amarradas,/ elas saltam, se beijam, se dissolvem, no céu livre por vezes um desenho,/ são puras, largas, autênticas, indevassáveis.

Logo nos três primeiros versos, o poema estabelece uma relação opositiva entre as palavras sono/outono e carne, indicando no quarto verso a liberdade do poeta no agenciamento das palavras e expressões a serem utilizadas no texto. Como intróito textual, estes primeiros versos introduzem logo a tônica do que será discutido posteriormente: o questionamento do fazer poético, sua tradição socioideológica. Ora, negar a rima entre sono e outono implica de saída a desmontagem de um certo servilismo do artista na construção do poema, implicando uma crítica à poesia de base tradicionalista antes preocupada com o caráter formal do texto, ligada mais a uma concepção redutora de forma do que com o caráter formal-ideológico do poema. Assim, se estabelece a crítica de uma certa passividade contemplativa, estabelecida pelas palavras sono (adormecimento) e outono (decadência, velhice, impotência) no contexto sociocultural ao qual o poema está ligado: o período da segunda guerra mundial.

1. DRUMMOND, 1989. p. 7-194. 
É de fundamental importância o sentido opositivo que a palavra carne possui. Enquanto sono e outono trazem em si a idéia de obscuridade e abstração, carne possui semanticamente significados ligados a corpo e ação. Neste sentido, sono e outono estão no campo semântico do adormecimento, enquanto carne liga-se a despertar, desentorpecer. Tem-se a partir daí a colocação clara de que o poema ruma antes para a ação engajada, física, do sujeito diante do absurdo da guerra, em oposição a uma atitude de passividade e medo diante dos fatos.

No entanto, tal atitude do poeta não implica necessariamente a destruição total de todo o lirismo e de todo o "encantamento", pois os versos seguintes não só corroboram o que ficou dito nos primeiros versos, como também estabelecem uma relação entre a autenticidade das palavras e a possibilidade de nelas se inserir um conteúdo de base lírica e pessoal - "no céu livre por vezes um desenho" -, sem contudo se esquecer do fato de que o adjetivo impõe a reflexão na medida em que o céu nos primeiros anos da década de 40 está quase sempre habitado pela tecnologia da guerra, além de ser a partir daí espaço privilegiado na lógica das batalhas: lirismo possível e necessário, mas quando e onde?

A segunda estrofe do poema é aberta com um verso de caráter nitidamente autobiográfico - "uma pedra no meio do caminho" -, situando o poeta e sua atividade no contexto semântico para o qual o poema seguirá, diretamente relacionado com o que ficou exposto anteriormente: o direcionamento do texto para a ação, convidando como co-participante de tal atitude a referência a outros poetas, atitude político-ideológica que chega quase a confundir o trinômio artista-arte-vida, arrrematado com o verso "é toda minha vida que joguei”.

Este direcionamento do texto para a atitude engajada não pode confundir o leitor, dando a impressão de uma estética ligada à idéia do fazer poético como expressão de uma subjetividade todo-abrangente, de um ser revoltado pelos horrores da guerra e que deseja projetar seu repúdio através de uma expressão lírico-pessoal. Aqui a subjetividade apresenta-se em estado conflitivo na medida mesma em que o poeta está sempre fazendo referência a

2. É bom não confundir engajamento com um sentido fechado, servil e populista de direcionamento partidário do texto, que tem levado muitos autores e críticos à produção de verdades demagógicas. 
uma espécie de não-eu, dialogando com um Outro, seja claramente explicitado Vinícius, Murilo, Neruda, Apollinaire e Maiakovski -, ou posto de modo mais sutil, numa quase humanização das palavras no último verso da primeira estrofe - "são puras, largas, autênticas, indevassáveis".

Tal atitude se configura mais claramente na estrofe seguinte: "Estes poemas são meus. É minha terra/ e é ainda mais do que ela. É qualquer homem/ ao meio-dia em qualquer praça. É a lanterna/ em qualquer estalagem, se ainda as há."

A subjetividade lírica é logo confrontada com uma espécie de abertura, no sentido de impor antes um significado ao mesmo tempo particular e geral. É este conflito entre o Eu e o Outro na poesia drummondiana que vai levar Antônio Candido ${ }^{3}$ a formular a idéia de que a poesia do poeta mineiro pauta-se numa espécie de inquietação jamais resolvida entre uma voz sempre tendente a presentificar o subjetivo e uma espécie de superego que impõe o confronto com a realidade sociocultural. Assim a poética de Drummond se situaria na tortuosa fronteira entre a expressividade e a referencialidade, para usarmos os termos de Roman Jakobson.

Ora, sendo justamente a partir deste conflito que se situa a aventura poética drrummondiana, a inquietação está em não conseguir decidir por uma poesia da expressividade ou de uma total integração com o mundo circundante. No poema de Augusto de Campos, ${ }^{4}$ esta relação se coloca de outra maneira. Sendo um texto intersemiótico, que insere no seu espaço textual outra forma de textualidade além do código lingüístico, o poder corporal da visualidade consegue dar uma funcionalidade maior à "presentificação" do que chamaríamos de objeto, numa acepção peirciana. O caráter sinestésico da página escura instaura logo uma atmosfera sombria que será particularizada pelo aparato verbal do poema. A presença da realidade circundante - "dark dark dark" - é corporalmente exposta logo ao primeiro contato com o texto, sendo, assim, uma certa inefabilidade, ${ }^{5}$ encontrada no texto drummondiano, como conseqüência do conflito, afastada pela materialidade da imagem.

É importante notar que os três primeiros versos do texto de Augusto de Campos - "dark dark dark/ vazio/ do quazar ao quark" - verbalizam o que

3. CANDIDO, 1995. p. 111-146.

4. CAMPOS, 1994

5. Inefabilidade deve ser entendida como dificuldade em nomear. 
o fundo negro da página presentifica em bloco, a escuridão; incluindo aí a negatividade através do vazio tanto verbal quanto espacial da segunda estrofe. Na poesia de Augusto de Campos há comumente a colocação de palavras e expressões em outros idiomas, o que parece estar ligado a um processo de questionamento e/ou abertura da subjetividade, que propõe que, através das agruras do eu, a coletividade, a babel de linguagens que é o mundo contemporâneo, esteja aí representada pela riqueza idiomática e pela utilização de outros códigos para além do contexto singular do poeta: a crise da consciência individual é a crise de todas as consciências individuais e, por tabela, da própria coletividade. Em Bio, o verso citado liga-se a tal processo conflitivo que, juntamente com toda a primeira estrofe, antecipa o vazio espacial, pictural, situado entre a primeira e a segunda estrofes.

A abertura da palavra título no oitavo verso revela o questionamento da individualidade, direcionando o texto para a discussão em torno do Brasil pós-64. A pergunta que o eu-lírico se faz remete a uma preocupação bem particular do homem contemporâneo: o mal-estar causado pela desintegração total das verdades que fincavam a individualidade desde o Iluminismo. Se a descoberta (exploração) de "mundos inexplorados", de novas realidades, tanto dentro quanto fora da subjetividade, o que pode ser visto no poema de Drummond, foi a grande marca do homem ocidental a partir da ruptura com o Feudalismo, ${ }^{6}$ o homem contemporâneo sente-se avassalado pela inquietante descoberta do caráter ideológico e até certo ponto ilusório da idéia de um Eu autônomo, todo suficiente, que pela razão poderia abarcar toda a complexidade do universo. A rachadura dos pontos de fixidez dá ao homem hodierno uma sensação de inadaptabilidade, que luta para reencontrar a identidade perdida, o ponto fixo, numa busca vertiginosa. No poema de Augusto de Campos, o uso do vocábulo "Bio", de natureza bastante abrangente, corrobora a incerteza do que se é e do que se deseja. Aqui fecha-se um círculo: o Eu que atormentava Drummond ressurge com novas características, tipicamente contemporâneas.

Se o poeta mineiro sempre esteve às voltas com elementos subjetivantes que, a despeito de sua vontade, teimavam em vir à tona explícita e implicitamente, como alusão à família e à terra natal, não raro contundentemente problematizados, como vimos anteriormente, tal problematização da subjetividade, da transposição do Eu em forma poética dá-se em função de sua

6. CONNOR, 1993. 
não-aplicabilidade a um mundo assolado por uma grande guerra e, para o poeta, carente de valores que respeitem a figura humana e a união dos povos. A não funcionalidade dos elementos subjetivos, pessoais faz com que o poeta tente afastá-los, mas não o leva a questionar a própria subjetividade enquanto valor de fixação de uma verdade existencial, ou seja, o poeta ainda acredita na sua importância, descrendo apenas de seu valor comunicativo em tal contexto, o que o leva à busca de reintegrar poesia e coletividade. Sendo assim, a problematização em Drummond é antes de ordem pragmática que semântica. No poema de Augusto de Campos tem-se um questionamento do próprio sentido da subjetividade, abrindose para uma discussão de ordem ontológica; a preocupação não está no caráter disfuncional da expressão subjetiva, mas principalmente na não-existência de uma subjetividade redentora; é antes uma preocupação do sentido da própria subjetividade: sentido do Eu e do Outro.

Cabe ressaltar porém o aparato crítico de que dispõe o poeta mineiro em sua relação com a subjetividade, pois, embora não atingindo o cerne de seu caráter ideológico, como se percebe em Augusto de Campos, está claro que o processo inquietante não permite ao poeta estabelecer o culto excessivo da referência, da comunicabilidade, que também é questionada, já que a fixação de uma verdade unicamente direcionada para o Outro seria o fim do próprio poético e sua substituição por algo como uma espécie de jornalismo demagógico. Daí que a crítica à imposição do Eu não permite a Drummond eleger o código do Outro como paradigma de sua poesia, nascendo daí uma poética da subjetividade que se problematiza, algo novo na tradição poética nacional, mas que permanece como memória; a referencialidade, nele, se impõe como esperança: "Poeta do finito e da matéria,/ cantor sem piedade, sim, sem frágeis lágrimas"; e " que se depositem os beijos na face branca, nas principiantes rugas/ o beijo é um sinal, perdido embora,/ da ausência de comércio,/ boiando em tempos sujo".

Em vista disso, resta a questão: como se caracterizaria o canto drummondiano?

O canto como problematização do poder da poesia de nomear o passado, dado o mal-estar com relação a este mesmo passado, está no âmago da aventura drummondiana, se relacionando com o inferno da nomeação do Outro e da própria experiência pessoal, restando ao poeta formulá-lo a partir desta inquietação que o impede de um relacionamento ingênuo com o seu fazer e com a realidade que ele veicula. Temos então que o problema, se dando na consciência, é indiscutivelmente um problema do poeta e de seu 
relacionamento com a linguagem, pois desconfiança em relação à tradição poética e seu conflito com a realidade presente nada mais é que um conflito instaurado dentro da própria linguagem. Estando descrente dos valores que tenta veicular, sejam eles de índole pessoal ou social, o poeta passa inquestionavelmente a problematizar o próprio código que utiliza, instaurando um afastamento conflitivo entre o que pretende dizer e a estrutura formal-ideológica do código utilizado.

Esta desconfiança extremamente desconfortável, e que é a principal característica da poesia moderna verdadeiramente crítica, é a instauração da metalinguagem como única possibilidade de veiculação de uma verdade que se alimenta incessantemente da voz dissonante que sussurra ser ela uma mentira. A metalinguagem é a única possibilidade dada à consciência de veicular algo que se alimenta de um vácuo: o silêncio. Sendo das funções jakobsonianas aquela que surge com a imposição do silêncio, a metalinguagem é sua filha bastarda, sua ovelha negra; ouçamos o poeta:

Como fugir ao mínimo objeto/ ou recusar-se ao grande? Os temas passam,/ eu sei que passarão, mas tu resistes,/ e cresces como fogo, como casa,/ como orvalho entre dedos,/ na grama, que repousam.

Vê-se claramente que o canto antes de estar situado na consciência se insere no cerne do ser, é antes uma necessidade vital que a imposição de um desejo circunstancial. No fragmento transcrito, observa-se uma diferenciação entre o canto e os fugazes temas que ele veicula. Não seria exagero afirmar que na experiência do poeta o canto é o formador da própria verdade existencial e sua procura não é só a procura do sentido por ele passível de veiculação, mas antes a busca da instauração do ser.

É importante observar como é construído o suporte imagético do fragmento acima transcrito. A partir da quarta estrofe, o poema começa a incorporar de modo mais sistemático uma linguagem evocativa de espaços e tempos distantes, ao mesmo tempo em que começa a estabelecer uma relação entre o canto e a natureza como no belo complexo imagético que se instaura quando da sua comparação com o orvalho entre dedos na grama. A aproximação com os elementos naturais reforça a idéia da vitalidade do canto como forma de estar no mundo e com ele, aproximação entre o homem e a natureza, única maneira de desbloquear a consciência do silêncio fatídico que a aprisiona. No entanto, tal aproximação não possui nenhum caráter neo-romântico ou postula um arcadismo atemporal, o que seria ingênuo e anacrônico, pois é da desconfiança 
dessas verdades que ele surge, inserido também como ato crítico do contexto sociocultural, como utopia de transformação:

Ele é tão baixo que sequer o escuta/ ouvido rente ao chão. Mas é tão alto/ que as pedras o absorvem. Está na mesa/ aberta em livros, cartas e remédios./ na parede infiltrou-se. O bonde, a rua,/ o uniforme de colégio se transformam,/ são ondas de carinho te envolvendo.

Problematizado desta maneira, o canto instaura-se como procura, como viagem, como algo em que o acesso definitivo se pauta, numa impossibilidade, já que a linguagem utilizada para buscá-lo é insuficiente, conseguindo no máximo apreender um instante cuja relação com o instante primeiro é apenas circunstancial e deteriorada, como bem observou João Alexandre Barbosa.

É a instauração do poético como procura que faz da poesia de Carlos Drummond de Andrade um divisor de águas na consciência poética nacional. Problematizando o passado e o presente, ao mesmo tempo que preso a eles por um compromisso histórico-pessoal, o futuro torna-se a busca de uma verdade, cujo único consolo está em procurá-la, sabendo-se da impossibilidade de exprimi-la dada sua relação intrínseca com um silêncio anterior à fala: "Já agora te sigo a toda parte,/ e te desejo e te perco, estou completo,/ me destino, me faço tão sublime,/ tão natural e cheio de segredos,/ tão firme, tão fiel... Tal uma lâmina,/ o povo, meu poema, te atravessa”. Assim, o poeta projeta o desejo de sua busca sabendo que é proporcional a ela a fuga do objeto procurado, ciente de que a incompletude se dá no momento mesmo em que o poeta assume o desejo como um ato, quase utópico, de nomear. O arremate final do poema possui uma força tal que se mostra como paradigmático da trajetória do poeta mineiro: a relação entre o poema (personificação e espaço do canto) e o povo.

A singularidade da construção do último verso está em colocar num mesmo nível espacial e semântico o povo e o poema, ambos sofrendo a ação instaurada pelo verbo atravessar. Tal relação equiparativa é antes o direcionamento da procura do que a crença de que no povo estaria a saída para a afasia que envolve o poeta, o que daria um teor demagógico ao texto. A busca da presentificação de uma realidade primordial instaura-se como irmanação 
entre o Eu e o Outro, numa procura agora de caráter social e político. É como se o poeta reformulasse o que colocou em Mão dadas: sigamos juntos à procura não só da transformação do mundo presente, mas principalmente à procura do canto fundador e inexprimível.

Isto posto, convém voltar ao poema de Augusto de Campos. "desvão/ ou desvio/ do olhar que me desleu/ que bio/ sou/ eu". O jogo paronomástico das palavras desvão/desvio estabelece a oposição entre os termos para além dos seus significados habituais, através do desmembramento das palavras a partir do processo de prefixação: dês-vão - banalidade, futilidade do leitor, mesclado ao sentido primeiro do vocábulo, espaço intersticial entre dois corpos; des-vio - despreparo do leitor no ato receptivo, de base visual, além de mudança de direção e incoerência. É de suma importância observar a associação entre olhar e ler (no caso, desler). Mais do que a leitura tradicional, o poema faz referência à leitura como processo de ligação entre o ato de decodificar o código verbal e a apreensão sinestésica dos elementos visuais: o olhar que desvia, não vendo, deslê ou lê em vão.

Ao teor interrogativo dos versos até aqui mencionados, somam-se os versos finais do poema - "micro ou macro/ clown ou clone/ sombra/ simulacro/ a sonhar/ insone" - em que se mesclam os questionamentos do eu em relação à vida e ao mundo, com uma preocupação de ordem metalingüística. A identificação do poeta como ser marginal, boêmio e desarticulador da ordem social, advinda do romantismo e radicalmente explorada pela poética modernista, é ironicamente questionada aqui: as fronteiras entre o clown e o clone no mundo contemporâneo passa a ser problemática, erguida por um muro de papel facilmente perfurável, no qual o conceito de marginalidade (clown) tornase não aplicável em face a um mundo ávido pela incorporação de novos modelos comportamentais aos clichês que entulham o imaginário pós-modernista com a única finalidade de incorporá-los (cloná-los), num círculo vicioso onde a figura do marginal nada mais é que um componente privilegiado do sistema.

Esta mistura entre auto-análise e metalinguagem poética é responsável pela instituição do caráter "não-utópico" do elemento subjetivo posto no poema, pois, se a atitude lírica impõe uma permeação entre o sujeito observador e o objeto observado, essa poética propõe uma concepção lírica que desestabiliza a relação "idílico-copulatiuva", nas palavras de Pignatari, entre os elementos envolvidos, criando uma espécie de lirismo vigilante (insone) que questiona tanto o mundo circundante (o objeto), quanto o próprio sujeito 
observador e seu olhar. A retomada lírica no poema de Augusto de Campos surge agora permeada por uma racionalidade, quebrando a identificação e problematizando todos os componentes envolvidos. Ou seja, vendo de modo retrospectivo, o texto retoma da poética drummondiana um dos seus aspectos definidores - a inquietação com a subjetividade, no entanto incorpora a ela a marca do contexto contemporâneo, da mente consciente de que nenhum espaço temático privilegiado possa vir desafogar o conflito em que está imersa a consciência, pois tanto a crença na expressão subjetiva é posta em suspensão, quanto o direcionamento para uma noção fechada de verdade. Aqui, as grandes verdades são postas sob suspensão. Não há, como em Drummond, poeta da inquietação, a procura da presentificação via algo passificador.

A diferença pode ser melhor percebida se observarmos como o silêncio se apresenta na poética de ambos: em Drummond, sendo na verdade a matriz e o produto da experiência poética, está na relação entre o nomear e o recalcar, no desvão, diríamos, no interstício, servindo de inferno fundador, asfixiante; em Augusto de Campos surge agora desconstruído, assumido em sua carga de significação aquém e além de qualquer linguagem, perde seu sentido pejorativo; desconstruído, descontrói, seja através da auto-ironia, seja contaminado pela visualidade, sinestesicamente aproximando aquele que percebe do objeto percebido. O que têm em comum: o caráter fundante do silêncio, só que em Augusto de Campos sem o teor infernal, e por que não quase místico, claramente presentes em Drummond. Assim, sendo infernal em Drummond, pode-se observar uma ânsia em nomear, em compartimentalizar, em categorizar: "a linguagem é conjugação significante da existência e é produzida pelo homem para domesticar a significação", a inquietação em Drummond surge da impossibilidade de fixidez; o silenciamento assumido como elemento de significação, desconstrutor da idéia de resto da linguagem está em Augusto de Campos como, ainda Orlandi, "a possibilidade para o sujeito de trabalhar sua contradição constitutiva, a que o situa na relação do 'um' com o 'múltiplo', a que aceita a reduplicação e o deslocamento".

Abstract: The proposal of this small paper is to establish a correlation

8. ORLANDI, 1995. p. 63.

9. ORLANDI, 1995. p. 15. 
among the poets Carlos Drummond de Andrade and Augusto de Campos, trying to propose a possible tradition of the contemporary Brazilian poetry, open for Drummond and radicalized by Campos: the problematization of the national subjective tradition, accentuating the identities and differences among these two poets.

Key words: tradition, national, identity.

$$
\text { Referências Bibliográficas }
$$

ANDRADE, Carlos Drummond de. A rosa do povo. São Paulo: Círculo do Livro, 1989.

BARBOSA, João Alexandre. Silêncio \& palavra em Carlos Drummond de Andrade. In: . A metáfora crítica. São Paulo: Perspectiva, 1974.

CAMPOS, Augusto de. Despoesia. São Paulo: Perspectiva, 1994.

CANDIDO, Antonio. Inquietudes na poesia de Drummond. In: Vários escritos. São Paulo: Duas Cidades, 1995.

CONNOR, Steven. Cultura pós-moderna. São Paulo: Loyola, 1993.

ORLANDI, ENI P. As formas do silêncio. Campinas: Unicamp, 1995. 